\title{
Study of the Integrated Risk Management of Construction Project Based on Knowledge Integration
}

\author{
Rong Zhu* \\ Anhui Xinhua University \\ Hefei, PR China, 230000
}

\author{
Sudi Gao \\ Anhui Xinhua University \\ Hefei, PR China, 230000
}

\begin{abstract}
This paper explains the connotations of the integrated risk management of construction project and knowledge integration, analyzes the object of knowledge integration in risk management, puts forward knowledge management circle according to PDCA circle in project management, and knowledge integration model of the integrated risk management of construction project.
\end{abstract}

Keywords-integrated risk management of construction project; knowledge integration; knowledge management circle

\section{INTRODUCTION}

In our country, with the change of economic structure, the market competition becomes more and more intense, the investment of engineering construction project is gradually increased, the production cycle is longer, the project construction process is facing more and more risks. People's risk awareness is gradually increasing. The diversification of the investment main body also brings the new management idea and the higher risk consciousness, some large-scale construction projects begin to adopt various risk management technology to improve the project benefit. The integrated risk management of construction project is becoming a research focus of construction risk management due to synthesize both merits of overall project risk management theory and total lifecycle risk management theory. The integrated risk management of construction project is an knowledge intensive job which can not exist without knowledge application. Improvement of integrated management' effect and efficient needs lots of information as well as knowledge comprehensive application and efficient flow. Knowledge integration is becoming more and more important in, and even the core of, the integrated risk management of construction project. Presently research about integrated risk management of construction project most base on risk management process, risk analysis technology, risk goal and risk management mode as well as methods integration, research concern on knowledge integration about integrated risk management of construction project is few.

*Corresponding author

\section{INTEGRATED RISK MANAGEMENT OF CONSTRUCTION PROJECT AND KNOWLEDGE INTEGRATION}

\section{A. Connotation of Integrated Risk Management of Construction Project}

Definition of integrated risk management of construction project has not been seen in present papers. Definition of construction project integration management can be found in the paper. Base on this, Yunli Gao defined integrated risk management of construction project. Integrated risk management of construction project is a high efficient project risk management model based on information technology. The model is taking the aim at realization of risk management objectives. All the project risks are analyzed, identified and evaluated systematically in the model. Requirements and cohesive relationships of phases in the whole lifecycle from project establishment to delivery are considered synthetically. So as the relationships of project management elements and dynamic relationships among participation sides in project execution. All of these are according to characteristics of construction project risk in the model. The essence of integrated risk management of construction project is including all risk management processes, taking aim at achieving project management goals and managing all the risk factors systematically based on all lifecycle of construction project. Integrated risk management of construction project is application of integration theory in construction project risk management field and managing project systematically. With the development of project management and project risk management discipline, the research of project risk management is also in constant development.

\section{B. Connotation of Knowledge Integration}

Presently, relatively comprehensive description of knowledge integration considers knowledge integration synthesizes enterprise knowledge of different source, different level, different structure and different content. Then knowledge is rebuilt. Single knowledge, scattered knowledge, existed knowledge, new knowledge, tacit knowledge, explicit knowledge is synthesized into a new knowledge system. Knowledge is shared and utilization of knowledge is improved. A great deal of knowledge has been accumulated in the development and practice of project risk management. These knowledge can be integrated and used to produce 
knowledge base. People can use the knowledge base. And new knowledge is generated. Then the new knowledge can be used in the practice and improve risk management efficiency significantly. Knowledge integration in risk management is proposed as "Fig 1".

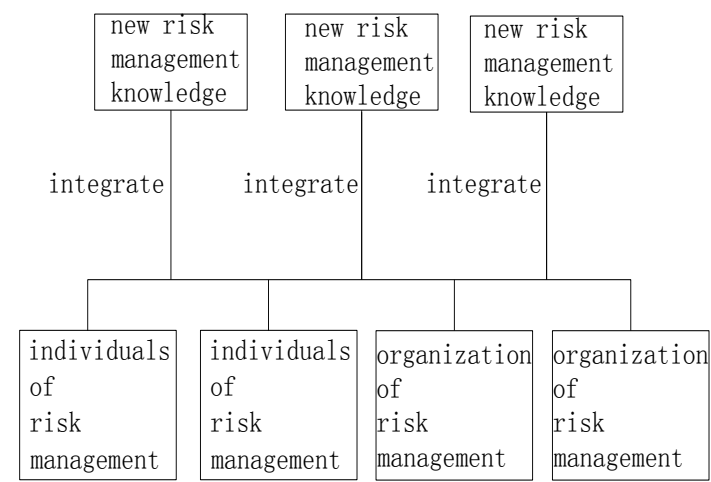

Fig. 1. Knowledge integration of risk management

Generally speaking, the process of management is the process of the integration of things. Risk management can promote the integration of risk factors, and ultimately form an organic system. It will make the human, financial, material, information, relations, time and other resources, to a certain extent, further integration. Through the engineering project risk management process of the data, the formation of new knowledge theory, and then further application, it will make the elements of the structure more reasonable.

\section{THE OBJECT OF KNOWLEDGE INTEGRATION ANALYSIS BASED ON INTEGRATED RISK MANAGEMENT OF CONSTRUCTION PROJECT PROCESS}

Integrated risk management of construction project process is mainly refer to integration of risk management process and project management process as well as integration between project risk management and project lifecycle. The process is generally as classification of risk management process in traditional sense. So the object of knowledge integration is analyzed by traditional risk management process. The process is risk identification, risk assessment, risk evaluation and risk control. Comparing to traditional knowledge of construction project risk management, construction project integrated management also includes knowledge of system theory, knowledge of system engineering, knowledge of integration theory, knowledge of integration method, and so on.

\section{A. Knowledge in Risk Identification}

Risk identification is very important to efficiency of risk management as the first step of risk management process. First risk identification needs to find out the possible risk factors from all the factors which influence the project. Then risk list is listed. Listing risk list need to design the format of the risk list. Commonly used methods of looking for risk factors are such as WBS (Work Break down Structure), brainstorming, Delphi method, influence diagram, check list method, scenario analysis, interview, and so on. Knowledge of risk identification mainly includes project information, finding out risk factors and judging the probability, properties of risk and loss caused by the risk, determination of risk factors, and so on. Most of these knowledge are tacit knowledge which are conserved in mind of managers. These knowledge are experiences which are accumulated during risk management study and work. If these knowledge can't be coded and integrated, they are can't be taken advantage of. It is not good for the formation of new knowledge.

\section{B. Knowledge in Risk Assessment}

Risk identification is a risk qualitative analysis process, and risk assessment is a process from qualitative to quantitative. Risk assessment is to estimate properties of risk and probability of risk occurrence during construction as well as the loss caused by the risk. Commonly, there are two ways of risk assessment. One is to estimate the risk objectively with application of risk management technology, according to the related data. The other is to judge the risk by risk managers of construction project who have experience in risk management. Knowledge in risk assessment is mainly formed in statistical process which implements the defamation of risk analytical information according to the probability of risk occurrence and the possible loss. These knowledge mainly includes mathematical statistics, probability, computer application technology, manager's judgment of risk, knowledge formed in previous risk assessment, and so on. These knowledge include both explicit knowledge and tacit knowledge. Integration of these knowledge are good for next risk assessment and formation of new risk estimate method.

\section{Knowledge in Risk Evaluation}

Risk evaluation is to determine risk level construction enterprise can be received from psychological of technical economy based on risk assessment and identification. Risk evaluation system is build by risk evaluation. The system can analyze ability that construction enterprise can sustain the risk qualitatively and quantitatively. Risk evaluation includes a lot of subjective experience and experience judgment. Scientific determination of project risk evaluation system requires a lot of knowledge according to the construction enterprise. Knowledge in risk evaluation is formed in establishment of risk evaluation system, determination of project risk, qualitative and quantitative analysis of ability to withstand risk. These knowledge mainly includes design of risk evaluation system, qualitative and quantitative methods of risk analysis, systems engineering methods as well as knowledge formed in previous establishment of risk evaluation system, risk managers' experiences, and so on.

\section{Knowledge in Risk Control}

Risk control is the objective and end of risk management. Construction project risk control is a process that construction project risk managers or organization prevent the identified risk factors or impose on the control object. So risk uncertainty can be reduced and the objective of risk 
aversion or reduction can be achieved. Different system goals require different ways of controlling structure. Different control methods correspond to different risk environment. How to achieve the risk control goal and choose the best control method in risk control process requires a process of knowledge accumulation and deepening. Knowledge formed in risk identification, assessment, evaluation, control can also be integrated into new knowledge.

\section{KNOWLEDGE INTEGRATED MODEL OF CONSTRUCTION PROJECT INTEGRATED RISK MANAGEMENT}

Research of knowledge integrated model of construction project integrated risk management requires study on knowledge management process.

\section{A. Process of Knowledge Management}

Process of knowledge management includes four steps. They are knowledge acquirement, knowledge processing, knowledge sharing, knowledge innovation.

1) Knowledge acquirement: Knowledge acquirement is mainly to collect all kinds of data, documents, reports, technology exchange, and so on. Classification of knowledge acquirement by policy or mechanism can be divided into knowledge acquirement by rote or mechanical copying, condition radioactive knowledge acquirement, knowledge acquirement from instruction, deductive knowledge acquirement, inductive knowledge acquirement, guess-proved knowledge acquirement, feedback amend knowledge acquirement, analogical knowledge acquirement, associative knowledge acquirement, epitomical knowledge acquirement.

2) Knowledge processing: Knowledge processing is to analyze results of knowledge acquirement, classify them, and store to the knowledge base. Knowledge processing is a process that refines the acquired knowledge. Knowledge is classified and stored by knowledge processing. Then these knowledge can be reprocessed conveniently. Knowledge processing provides the basis for knowledge innovation.

3) Knowledge sharing: Knowledge sharing is to establish a knowledge and expert base that is convenient for staffs to study and contact in time. Knowledge sharing is based on network platform. Knowledge mainly includes three aspects. On the one hand, knowledge processed is coded and stored in knowledge base of the enterprise. On the other hand, expert base is formed by establishing data for experts who own them and knowledge owners of knowledge hasn't been refined. The third aspect is that staffs can share their learning experiences and integrate new knowledge.

4) Knowledge innovation: Knowledge innovation is to improve existed process, induce new knowledge and share new view or new experiences. It is a sublimate process for existing knowledge. Knowledge innovation may come from combination of old knowledge, or new knowledge totally different from previous. Knowledge transformation is achieved by these steps. Knowledge usually transfers between individuals, between individual and enterprise. Then new knowledge is formed. The four steps of knowledge management is shown in "Fig. 2".

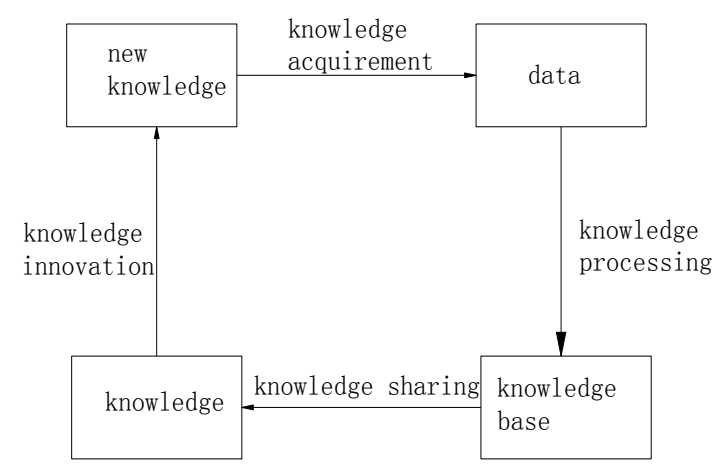

Fig. 2. Process of knowledge management

\section{B. Knowledge Management Circle}

Knowledge management circle is good for knowledge integration. It is formed by combination of comprehensive system view, knowledge management process and PDCA circle theory in total quality management. Knowledge management circle is shown as "Fig. 3".

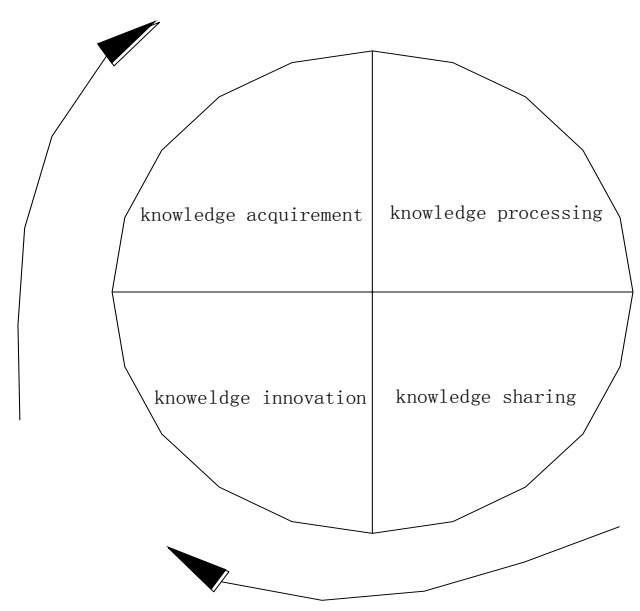

Fig. 3. Knowledge management circle

There are three features of knowledge management circle.

1) Dnamic circle: Knowledge management circle is not over by running once but start from beginning to end again. On one hand knowledge management circle is running during all life circle of project risk management from one phase of construction project risk management to another. Then knowledge integration can be achieved. On the other 
hand the problems and experiences that encountered when knowledge circle is running can provide valuable experience to next circle.

2) Big circle with small circle: Dueing to numerious participants of construction project, different participants meet different risks. The knowledge is different. And usually there is not special organization of risk management in each participants. Risk manangement organization of construction project is generally fragment. Risk management of different departments and different levels is totally different. Knowledge management circle of project knowledge is formed during process of knowledge management.

3) Stepped rise: Knowledge management circle can not only cycle on one level. Process of knowledge integration is a process that knowledge integrated level improved continuously. Knowledge integrated level can be improved by years of accumulation and circulation. A comprehensive scientific knowledge system of construction project risk management is formed. And the level of integrated risk management of construction project can also be raised. Risk can finally be controlled.

Knowledge integration is a continuous process that need knowledge management proceeds in risk managgement continuously. All cycle of risk management is devided in four phases. They are risk identification, risk assessment, risk evaluation, and risk control. Different phases all need to run knowledge circle. The level of knowledge integration is raised gradually. And the level of risk management is rising corresponding to the rising level of knowledge integration. Level of risk managers can also be improved. So knowledge integration model can be obtained through this. The model is shown in "Fig. 4".

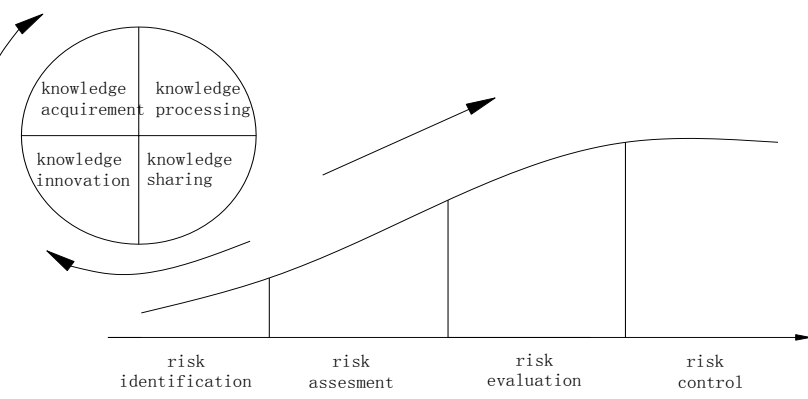

Fig. 4. Knowledge integrated model of construction project integrated risk management

\section{THE COMPLEXITY OF KNOWLEDGE INTEGRATION RISK MANAGEMENT}

\section{A. Comprehensive}

Knowledge integration management brings together a large number of risk information, including human, financial, material, information, time and other elements. The scope of its management is more extensive, involving almost all of the software and hardware elements, especially related to the re creation of knowledge. From the view of management technology and method, the risk management of knowledge integration involves not only the management technology itself, but also the integration of other disciplines.

\section{B. Variability}

- The risk management system of knowledge integration has the structure of multi level and multi function;

- In the process of the formation and development of the knowledge integration risk management system, the function and the level of the knowledge integration risk management system will be continuously reformed and improved;

- The risk management system of knowledge integration will evolve with the change of environment.

\section{Cooperativity}

The goal of knowledge integrated risk management is to realize complementary system by the integrating of knowledge, which requires the integration of management elements in accordance with a certain way of integration, a coordinated and orderly system is bigger, the risk management function of the system is strong. The greater the degree of order of this risk management system, the stronger the overall functional performance of the system.

\section{Contradictoriness}

Project integration management needs to make a choice from the conflicting objectives. Therefore, it will bring more difficulties to the integration of knowledge. We all know that the project goal must be inter related and mutually influenced, and the change of a certain goal will cause the change of the other goals. For example, shorten the project duration will inevitably bring an increase in cost, and the reduction of the cost will lead to problems in the quality of the project, then the risk appears. Knowledge integration risk management system once formed, will effectively reduce the risk of this contradiction, so that the goal to achieve equilibrium. Therefore, the use of knowledge integration can effectively reduce the contradiction between objectives.

\section{E. Innovativeness}

Due to the integration of knowledge management is to highlight the subject of human behavior, and also the behavior of people emphasizes the creative thinking and innovation of management method, organizes the internal and external resources for effective integration and reconstruction, which can produce the effect that can not be achieved before integration. Therefore, the innovation of knowledge integration risk management is particularly important. 


\section{CONCLUSION}

Engineering projects, especially large and medium sized projects, is an extremely complex system engineering. In the implementation of the project, it is inevitable to be affected by the uncertain factors. If in the expected time, we can not complete the project in a certain level of security with reasonable project quality and project cost, the impact on the investment benefit of fixed assets is enormous. The uncertainty that causes the project to reach the expected target is the risk of construction project. Both at China and abroad, it is generally considered that the project construction project is a very risky activity. Project risk management must be carried out in order to ensure that the project can achieve the expected goal, so that the project participants can get the expected return.The application of knowledge integration in integrated risk management of construction project can greatly improve efficiency of risk management, risk management level of managers'and project department's as well as enterprise's. And the risk management knowledge system of construction project is riched. The risk management level of the whole industry is improved.

\section{REFERENCES}

[1] Wang Juan-ru, Zhao Song-zheng, Yang Jin. Study the conditon and model of knowledge integration, J. Forcast. 23 (2004) 66-70.

[2] Li Hong-yan. The knowledgeable integrated mechanism of risk management and managerial strategies, J. Wuhan university of technology (Social Science Edition). 18 (2005) 217-219.

[3] Zhang Guo-zong, Chen LI-wen. Heavy section builds the project administration knowledge integration, J. Technoeconomics \& Management Research. 30 (2010) 92-96. 